\title{
Researches in National Institute of Radiological Sciences (NIRS) for radiation protection of non-human biota and ecosystems in Japanese environment
}

\author{
S. Yoshida, N. Ishii, Y. Ishikawa, I. Kawaguchi, Y. Kubota, K. Tagami, \\ H. Takeda, M. Doi, T. Nakamori, T. Ban-nai, A. Fujimori, S. Fuma, \\ K. Maruyama, T. Yasuda, K. Yanagisawa, K. Miyamoto and Y. Watanabe \\ National Institute of Radiological Sciences, Anagawa 4-9-1, Inage-ku, \\ Chiba-shi, 263-8555 Chiba, Japan
}

\begin{abstract}
This paper summarizes research activities in National Institute of Radiological Sciences (NIRS) for evaluation of the radiation effects on selected terrestrial and aquatic organisms as well as the ecosystems. Seven organisms, conifers, fungi, earthworms, springtails, algae, daphnia and Medaka are presently selected to study. For the estimation of possible radiation dose, transfers of radionuclides and related elements from medium to organisms are evaluated. Dose-effect relationships of acute gamma radiation on the survival, growth, and reproduction of selected organisms have been studied. Studies on the effect of chronic gamma radiation at low dose rate were also started. In order to understand the mechanism of radiation effects and to find possible indicators of the effects, information of genome- and metagenome-wide gene expression has been collected. Evaluation of ecological effects of radiation is more challenging task. Study methods by using three-species microcosm were established, and an index for the holistic evaluation of effects on various ecological parameters was proposed. The microcosm has been simulated as a computer simulation code. Developments of more complicated and practical model ecosystems have been started. The Denaturant Gradient Gel Electrophoresis (DGGE) has been applied on soil bacterial community in order to evaluate the radiation effects on soil ecosystems.
\end{abstract}

\section{INTRODUCTION}

Present system of radiation protection has been developed in order to protect human. On the other hand, increasing attention has come to be focused on the protection of the environment, i.e., non-human biota and ecosystems, from ionizing radiation, over the last decade. Several international organizations, such as International Commission on Radiological Protection (ICRP), International Atomic Energy Agency (IAEA) and United Nations Scientific Committee on the Effects of Atomic Radiation (UNSCEAR), organized the meetings on this matter. The ICRP established "Committee 5" for the environmental protection in 2005, and put a new chapter entitled "Protection of the Environment" in the ICRP recommendation in 2007 [1].

A lot of efforts have also been put on the collection of available scientific data. European projects such as FASSET and ERICA [2] played important roles on it, and pointed out existing data gaps. The available transfer parameters of radionuclides for non-human biota are limited, since the pathways, which are not connected to human radiation dose, have not been well studied. The relevant scientific data of radiation effects are also limited especially for chronic exposures. Although the importance of ecosystem effects are pointed out, there is almost no way how to evaluate it. Further researches are required to get necessary parameters and to establish suitable methods for evaluation of radiation dose and effects. In addition, there is a need to collect scientific information in Asian countries including Japan, because of the differences in climate between Europe and Asia. Considering high population density and unique life style in Japan, we always have to think about the nature in our own "backyard" rather than that in remote area without any human activities. 
This paper summarizes research activities in National Institute of Radiological Sciences (NIRS) for evaluation of the radiation effects on selected terrestrial and aquatic organisms as well as the ecosystems.

\section{SELECTED ORGANISMS AND STUDY METHODS}

Among organisms, conifers, fungi, earthworms, springtails, algae, daphnia and Medaka are presently selected to study. Most of them play important roles in Japanese ecosystems and are possibly useful for bio-indicator of the radiation effects. Existence of standard methods for chemical toxicity tests is also one of the important factors to select the organisms, in order to compare the effects of radiation with those of another toxicants.

Dose-effect relationships of acute $\mathrm{X}$ or gamma radiation on the survival, growth, and/or reproduction of selected organisms have been studied. Studies on the effect of chronic gamma radiation at low dose rate were also started. Information of genome- and metagenome-wide gene expression obtained by the High Coverage Expression Profiling (HiCEP) [3] has been collected, in order to understand the mechanism of radiation effects and to find possible biomarkers of the effects. Transfers of radionuclides and related elements from medium to organisms are evaluated for the estimation of possible radiation dose.

Since there was almost no data on the effects of radiation on ecosystems, we established study methods by using three-species microcosm, i.e., an experimental model ecosystem consisting of three species of microorganism. An index for the holistic evaluation of effects on various ecological parameters such as sizes of population or community was proposed. The population dynamics and mass and energy budgets of the microcosm have been simulated as a computer simulation code. Developments of more complicated and practical model ecosystems, multi-species microcosm, have been started. The Denaturant Gradient Gel Electrophoresis (DGGE) has been applied on soil bacterial community in order to evaluate the radiation effects on soil ecosystems.

In the present paper, we introduce our studies especially for springtails, conifers, Medaka, microcosm, and bacterial community.

\section{EFFECTS ON BIOTA}

\subsection{Springtails}

Soil invertebrates play an important role in the ecosystem function such as catalyzing the cycling of elements. Because of their ecological importance, they are increasingly used for ecological impact assessment of chemical substances for the terrestrial ecosystem in the international organizations such as the Organization for Economic Cooperation and Development (OECD) and the International Organization for Standardization (ISO).

In order to provide the basic data for radiation effects, dose-response relationships of gamma radiation on the survival, growth, and reproduction of the springtail, Folsomia candida, were studied in a standard laboratory test for chemical toxicity. F. candida was acutely irradiated, and subsequent survival, growth in body length, and number of neonate juveniles produced by irradiated specimens were examined [4]. The $50 \%$ lethal dose $\left(\mathrm{LD}_{50}\right)$ was $1360 \mathrm{~Gy}$, and the $10 \%$ and $50 \%$ effective doses $\left(\mathrm{ED}_{10}\right.$ and $\mathrm{ED}_{50}$ ) for growth were 32 and $144 \mathrm{~Gy}$, respectively. The $\mathrm{ED}_{10}$ and $\mathrm{ED}_{50}$ values for reproduction were 7 and $22 \mathrm{~Gy}$, respectively, indicating that the reproductive damage was the most sensitive radiation effect seen in F. candida.

Radiation-induced gene expression of $F$. candida was analyzed by using the HiCEP [5]. Several genes expressed in a dose-dependent manner were determined by sequencing analyses of the transcripts. The expression profiling should have a great potential to provide useful biomarkers for radiation effects on biota. 
The similar studies were performed for earthworm, Eisenia fetida. Transfers of radionuclides and stable elements from medium to earthworms are also evaluated as the basic information for dose estimation [6].

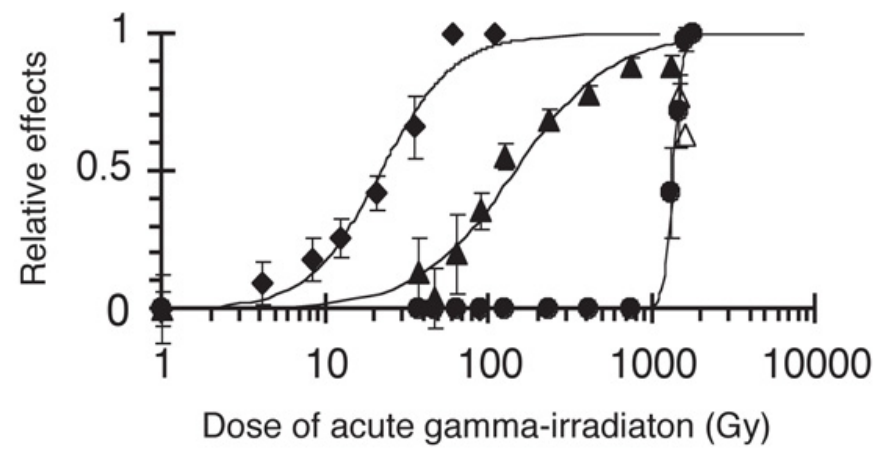

Figure 1. Effects of gamma irradiation on the survival $(\bullet)$, growth $(\boldsymbol{\Lambda})$, and reproduction $(\square)$ in Folsomia candida, 4 weeks after acute irradiation [4].

\subsection{Conifers}

After the Chernobyl accident, environmental effects of radiation appeared remarkably in conifers such as pine and spruce trees in the surrounding forests. Depending on the exposed radiation levels, the conifers showed growth inhibition, malformation of needles, reproductive loss and withering, which mainly resulted from cellular damages in proliferating points, meristem, in apical buds and root tips. For investigations of radiation effects on the proliferating cells in plants, in vitro cell cultures are as powerful as it is for investigation of proliferating cells in mammals. In this study, suspension cell cultures of Japanese native conifers, Japanese cedar (Cryptomeria japonica) and Japanese larch (Larix kaempferi), were used to elucidate cellular effects of ionizing radiation on conifers.

The coniferous cell cultures were analyzed for dose-response for ionizing radiation. Cell proliferation in the cell cultures was inhibited significantly by acute irradiation with X-rays at doses above $0.5 \mathrm{~Gy}$. A chronic irradiation with gamma rays also inhibited the cell proliferation at dose rates above $5.3 \mathrm{mGy} / \mathrm{h}$. The dose-response relationships in the cell cultures broadly correspond to the relationship between exposure levels and damages in the pine trees around the Chernobyl power plant after the accident. The growth inhibition observed was accompanied by an increase of cell death, which was characteristic of nuclear DNA fragmentation. These suggest that the apoptosis-like cell death should be involved in the susceptibility of conifers to ionizing irradiation.

The irradiated cells of Japanese cedar were analyzed also for gene expression to understand comprehensive biological response to ionizing radiation. The HiCEP was applied to the cell culture of Japanese cedar at $2 \mathrm{~h}$ after an acute irradiation (3 Gy). Among approximately 20,000 transcripts detected, 6 transcripts exhibited increasing expression by over 10 folds by the irradiation. Sequencing analyses of the transcripts have been preformed.

Distributions of radionuclides and stable elements within coniferous tree were also estimated as the basic information for dose estimation.

\subsection{Medaka}

Medaka (Oryzias latipes), the smallest freshwater fish in Japanese environment, has been used as model animal in many different fields of science including radiation biology. It is also useful for ecological 
impact assessment of chemical substances. One of the big advantages to use Medaka is transparency of its embryo.

The radiation effects on developing brains of Medaka were examined under a stereomicroscope in living embryos until hatching. Medaka embryos at 25-26 or 28-30 stages were acutely irradiated with $\mathrm{X}$-ray with doses lower than the $\mathrm{LD}_{50}$ of the embryos. All the irradiated embryos survived; however, from 6 to $35 \mathrm{~h}$ after X-ray irradiation, massive clusters of dead cells were observed either in the entire brain region or mainly in the optic tectum $[7,8]$. The number of massive clusters was dose dependent. These dead cells disappeared thereafter, and the irradiated embryos continued to develop apparently normally. The grown irradiated embryos, however, had smaller brains and eyes than the non-irradiated control embryos. At hatching, the irradiated embryos exhibited histological abnormalities in the brain, particularly in the torus longitudinalis, and in the retina, although most of them hatched normally. The results indicate that brain cell death and a reduced brain size can be observed in living irradiated embryos, and suggest that the Medaka embryo is useful for screening the developmental neurotoxicity effects of various hazardous factors.

\section{EFFECTS ON ECOSYSTEMS}

\subsection{Microcosm}

For better understanding of the environmental risks of ionizing radiation, it is important to evaluate ecological effects at the community-level, because ecosystems consist of many species with a wide range of sensitivities and interactions among those constituent species are complex. We therefore investigated effects of ionizing radiation as well as other toxic agents on ecological microcosm mimicking aquatic microbial communities, which play an important role in material cycles known as the microbial loop. We used two types of microcosm, i.e., three-species microcosm and multi-species microcosm.

The three-species microcosm consisted of flagellate alga (Euglena gracilis) as a producer, ciliate protozoa (Tetrahymena thermophila) as a consumer and bacterium (Escherichia coli) as a decomposer. This microcosm was exposed to gamma rays, ultraviolet (UV) radiation, acids or metals, and effects on cell densities were observed [9]. Effects observed in the microcosm were not only direct effects but also indirect effects due to interspecies interactions. The results were analyzed using the ecological effect index (EEI), in which degrees of differences in the cell densities between exposed and control microcosms were represented by the Euclidean distance function. A $50 \%$ effect dose for the microcosm $\left(\mathrm{ED}_{\mathrm{M} 50}\right)$, at which the EEI became $50 \%$, was evaluated to be $530 \mathrm{~Gy}$ for gamma rays, $2100 \mathrm{~J} / \mathrm{m}^{2}$ for $\mathrm{UV}, 4100 \mu \mathrm{M}$ for manganese, $45 \mu \mathrm{M}$ for nickel and $110 \mu \mathrm{M}$ for copper. An individual-based computer simulation model, SIMCOSM, was developed, in order to simulate the population dynamics and mass and energy budgets of the microcosm [10].

The multi-species microcosm consisted of eight identified microorganisms and bacteria has been used for ecological impact assessment of copper, some herbicides, insecticides and detergents in Japan [11]. In our study, the microcosm was acutely irradiated with gamma rays at 100, 500, 1000 and $5000 \mathrm{~Gy}$, and effects on populations were observed. The $\mathrm{ED}_{\mathrm{M} 50}$ was evaluated to be $2000 \mathrm{~Gy}$ for gammarays, $0.57 \mathrm{mg} / \mathrm{l}$ for copper and $49 \mathrm{mg} / \mathrm{l}$ for $2,4,5-\mathrm{T}$ (herbicide) when the microcosm was exposed to these toxic agents in the developing stage. It was also evaluated to be $5600 \mathrm{~Gy}$ for gamma-rays, $6.7 \mathrm{mg} / \mathrm{l}$ for benthiocarb (herbicide) and $6.1 \mathrm{mg} / \mathrm{l}$ for LAS (surfactant) when the microcosm was exposed in the steady state.

\subsection{Bacterial community}

Soil bacteria assume a vital role in the functioning of ecosystem such as nutrient cycling, organic matter formation and decomposition, soil structure formation, and plant growth promotion. In general, the effect of ionizing radiation on bacteria has often been studied by conventional methods based on 
cultivation of isolated bacteria. However, more than $90 \%$ of the bacteria existing in soil cannot be cultured on laboratory media. A vast portion of soil bacterial communities, therefore, remains unstudied. To overcome the drawbacks of these culture-dependent methods, molecular techniques are widely used in the last decade. In this study, DGGE based on the 16S rRNA gene sequence was applied to estimate the effect of ionizing radiation on soil bacterial community. In addition, release of metal ion and nutrients from soil was determined to assess potential impacts on the functioning of soil ecosystem [12].

Our results showed that chronic gamma irradiation at a dose rate of $1.2 \mathrm{~Gy} / \mathrm{d}$ to a paddy soil system changed both the bacterial community structure and the release of iron and sulfate. Although it is thought that bacteria are less sensitive to radiation exposure, metabolic activities of soil bacteria would be sensitive. Enhancing knowledge of those radiation effects will aid in the development of environmental radiation protection in ecosystem level.

\section{References}

[1] International Commission on Radiological Protection, ICRP publication 103: Recommendations of the ICRP (2007).

[2] Environmental Risk from Ionising Contaminants: Assessment and Management (ERICA): http://www.erica-project.org/.

[3] Fukumura R., Takahashi H., Saito T., Tsutsumi Y., Fujimori A., Sato S., Tatsumi K., Araki R. and Abe M., Nucleic Acids Res. 31 (2003) e94.

[4] Nakamori T., Yoshida S., Kubota Y., Ban-nai T., Kaneko N., Hasegawa M. and Itoh R., Ecotoxicol. Environ. Saf. (2007) doi: 10.1016/j.ecoenv.2007.10.029.

[5] Nakamori T., Fujimori A., Kinoshita K., Ban-nai T., Kubota Y. and Yoshida S., Environ. Sci. Technol. (2008) in press.

[6] Yoshida S., Muramatsu Y. and Peijnenburg W.J.G.M., Radioprotection 40 (2005) S491.

[7] Yasuda T., Aoki K., Matsumoto A., Maruyama K., Taguchi Y., Fushiki S. and Ishikawa Y., J. Radiat. Res. 47 (2006) 295.

[8] Yasuda T., Yoshimoto M., Maeda K., Matsumoto A., Maruyama K. and Ishikawa Y., J. Radiat. Res. (2008) in press.

[9] Fuma S., Ishii N., Takeda H., Miyamoto K., Yanagisawa K., Ichimasa Y., Saito M., Kawabata Z. and Polikarpov G.G., J. Environ. Radioactivity 67 (2003) 1.

[10] Doi M. and Kawaguchi I., J. Environ. Radioactivity 96 (1/3) (2007) 32.

[11] Takamatsu Y., Nishimura O., Inamori Y., Sudo R. and Matsumura M., Wat. Sci. Tech. 34 (1996) 61.

[12] Ishii N., Homma-Takeda S., Tagami K., Fuma S. and Takeda H., Int. J. PIXE 17 (2008) 161. 
